\title{
THE INFLUENCE OF NON-GEOMETRIC FACTORS ON THE SEISMIC BEHAVIOUR OF BRIDGES ON ISOLATING BEARINGS
}

\author{
by N. Cooke * , A. J. Carr* *, P. J. Moss** \\ and Tan Fun Kwai *.
}

\section{SUMMARY.}

A study of the sensitivity of bridge response to changes in nongeometric parameters was carried out using mainly the El Centro $1940 \mathrm{~N}-\mathrm{S}$ earthquake component. The response of bridge decks supported on elastomeric or a combination of elastomeric and lead-rubber bearings is computed. The effects of variations in the following parameters on response were studied;

a) a range of bearing properties,

b) a range of abutment stiffnesses and abutment weights,

c) different earthquake records and

d) the effect of seismic waves propagating at various velocities and angles of attack with respect to the bridge centreline.

\section{INTRODUCTION.}

The authors have described the influence that geometric factors such as pier heights (uniform or non-uniform) and the number of spans [1] have on the seismic response of bridges mounted on elastomeric bearings or a combination of elastomeric and lead-rubber bearings. Bridge bearings can be used to provide a measure of protection to the substructure by increasing the natural period of the bridge and in the case of lead-rubber bearings, the equivalent viscous damping. The consequence of using isolating bearings is that the response of the bridge to the earthquake is generally reduced.

\section{BRIDGE MODEL.}

The bridge modelled in this study consisted of four $20 \mathrm{~m}$ spans supported on rigid abutments and $1.676 \mathrm{~m}$ diameter piers, $10 \mathrm{~m}$ in height and fixed at the base. The deck comprised four standard prestressed concrete I-beams and a cast-in-situ reinforced concrete slab, $180 \mathrm{~mm}$ thick, continuous over the entire bridge.

Expansion joints were provided at the abutments; the latter were represented either as rigid or as flexible. The bridge was modelled in plan with a view to studying the transverse response to seismic excitation. The computer model used, is shown in Figure 1.

The first computer model represented the deck resting on four elastomeric bearings at each abutment $\left(k_{b}=3.68 \mathrm{kN} / \mathrm{mm}\right)$ and eight elastomeric bearings

\footnotetext{
* Former Research Student, University of Canterbury.

* * Senior Lecturer in Civil Engineering, University of Canterbury.
}

$(\mathrm{k}=7.36 \mathrm{kN} / \mathrm{mm})$ at each pier (Bridge \#10). In the second model, the deck rested on four lead-rubber bearings at each abutment ( $\mathrm{k}=5.4 \mathrm{kN} / \mathrm{mm})$ and $a$ combination of four lead-rubber bearings and four elastomeric bearings $\left(\mathrm{k}_{\mathrm{b}}=9.1 \mathrm{kN} / \mathrm{mm}\right)$ at each pier (Bridge \#l). Typical hysteresis loops for lead-rubber bearings and elastomeric bearings are shown in [1].

\section{VARIATIONS IN BEARING PROPERTIES.}

The actual properties of the bearings and dissipators will vary from the assumed design values because of random variations that arise during manufacture, and because they are sensitive to the magnitude of the vertical load and shear strain, both of which will vary along the bridge. Hence, bearings in any bridge will have different stiffnesses and in order to study the sensitivity of bridge response to variations in bearing properties a number of analyses were carried out with different bearing stiffnesses, strengths and postyield dissipator stiffnesses for the deck supported on a combination of elastomeric and lead-rubber bearings and rigid abutments (Bridge \#1). All the properties were varied by $+/-20 \%$ and the results of the different analyses are shown in Table 1 .

It shows that the natural period of the bridge could lie between 0.77 and 0.85 seconds, a range within which the spectral accelerations and displacements are generally changing rapidly. However, the variation in deck displacement at the piers is generally small, with maximum variations of $+4 \%$ and $-5 \%$ from the normal case, the exception being when both abutment bearing stiffnesses are $20 \%$ greater than the design value. In this case the maximum deck displacement is smaller by $11 \%$, and the abutment forces are greater by $14 \%$. Deck 


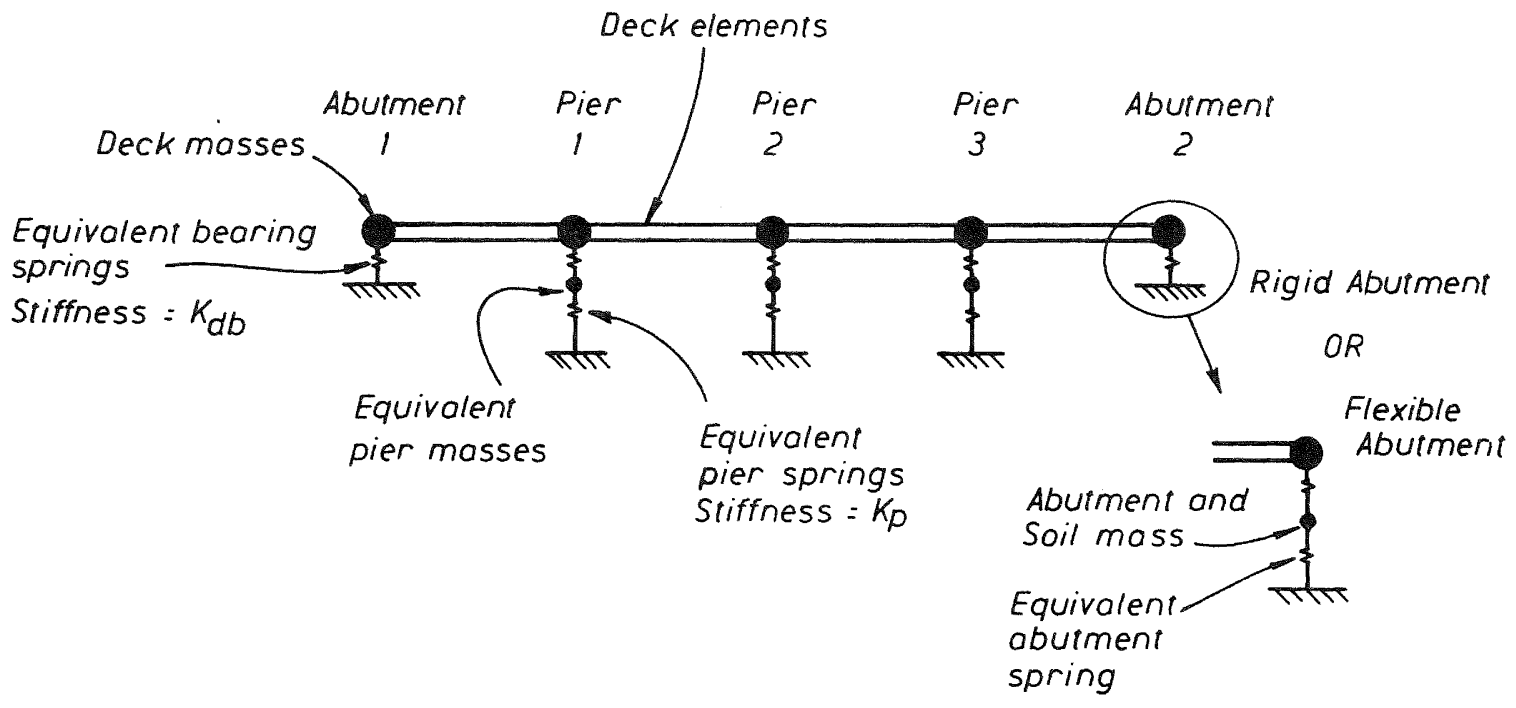

Figure 1. Bridge modelled in plan.

\begin{tabular}{|c|c|c|c|c|c|c|c|c|c|c|}
\hline \multicolumn{2}{|c|}{$\begin{array}{l}\text { Variation of Bearing } \\
\text { Stiffnesses }\end{array}$} & $\begin{array}{c}\mathrm{Nil} \\
\text { Variation }\end{array}$ & $\begin{array}{c}\text { Both } \\
\text { abutmentst }\end{array}$ & $\begin{array}{l}\text { Abutment } 1 \uparrow \\
\text { Abutment } 2 \downarrow\end{array}$ & All Pierst & All Pierst & $\begin{array}{c}\text { Both } \\
\text { Abutments } \downarrow \\
\text { All } \\
\text { Piers } \uparrow\end{array}$ & $\begin{array}{c}\text { Both } \\
\text { Abutments } \uparrow \\
\text { All } \\
\text { Piers }\end{array}$ & $\begin{array}{l}\text { Both } \\
\text { ibutmknts }{ }^{2} \\
\text { All } \\
\text { Piers }\end{array}$ & 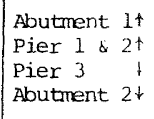 \\
\hline \multicolumn{2}{|l|}{ Bridge Number } & 1 & 2 & 3 & 4 & 5 & 6 & 7 & 8 & 9 \\
\hline \multicolumn{2}{|c|}{ Natural Period (sec) } & 0.81 & 0.77 & 0.82 & 0.81 & 0.81 & 0.85 & 0.77 & 0.77 & 0.82 \\
\hline \multirow{2}{*}{$\begin{array}{l}\text { Maximum } \\
\text { Deck } \\
\text { Displacement } \\
\text { (mm) }\end{array}$} & Abutment & 56.5 & 48.9 & 73.5 & 55.9 & 57.5 & 59.4 & 53.1 & 52.1 & 74.4 \\
\hline & Pier & 66.7 & 59.7 & 68.5 & 66.0 & 67.9 & 67.3 & 64.6 & 63.1 & 69.5 \\
\hline $\begin{array}{l}\text { Maximum } \\
\text { Bearing } \\
\text { Displacement } \\
\text { (mil) }\end{array}$ & Pier & 12.2 & 12.0 & 10.0 & 12.3 & 12.6 & 10.7 & 11.7 & 12.2 & 7.5 \\
\hline \multirow{2}{*}{$\begin{array}{l}\text { Maximum } \\
\text { Bearing } \\
\text { Force } \\
\text { (kN) }\end{array}$} & Abutment & 440.0 & 501.0 & 474.8 & 436.8 & 445.9 & 364.7 & 506.1 & 499.4 & 473.0 \\
\hline & Pier & 250.8 & 246.5 & 227.7 & 249.7 & 254.8 & 234.6 & 243.8 & 246.0 & 244.1 \\
\hline \multicolumn{2}{|c|}{ Maximum Pier Shear (kN) } & 314.2 & 308.1 & 326.8 & 318.0 & 317.6 & 324.8 & 310.0 & 308.8 & 312.9 \\
\hline
\end{tabular}

TABLE 1 Results of analyses for bearing stiffnesses Variation $\uparrow$ - Bearing stiffness increases by $20 \%$ $\downarrow-$ Bearing stiffness decreases by $20 \%$ 
displacements at the abutments vary much more than the deck displacements at the piers. When both abutment bearings are over-stiff the maximum deck displacement there is reduced by $14 \%$ but when one is over-stiff and the other under-stiff the maximum deck displacement increases to $30 \%$ above the design value.

The overall response of the bridge depends on the effective stiffness of the whole structure and the relative distribution of stiffnesses along the bridge. Although in general, an increase in bearing stiffness at a particular pier or abutment should be accompanied by a local reduction in deck displacement and increase in substructure force, this is not the case here. The reason for this is that the response of this bridge is sensitive to variations in abutment bearing stiffness and comparatively insensitive to variations in pier bearing stiffness. Deck displacements and bearing forces at the abutments directly relate to changes in local bearing stiffness variations, but this direct relationship does not hold at the piers.

The maximum deck displacement at the pier $(69.5 \mathrm{~mm})$ and at the abutment $(74.4 \mathrm{~mm})$ occurred in Bridge \#9, where the variation in bearing stiffnesses is antisymmetrical about the centre of the bridge; in this case, the deck both rotates and translates at maximum response. The maximum bearing shear strain at the piers was $13.5 \%$ for Bridge \#5, where the stiffness of all pier bearings were reduced by $20 \%$; this was also associated with the largest pier bearing force of $255 \mathrm{kN}$. The largest abutment bearing force was $506 \mathrm{kN}$, for Bridge \#7, where the abutment bearings were over-stiff and the pier bearings under-stiff. The largest pier shear force occurred in Bridge \#3, where the bearing stiffness was decreased at one abutment and increased at the other, resulting in a combination of rotational and translational response.

\section{VARIATIONS IN ABUTMENT STIFFNESS AND} WEIGHT.

The effects of changes in abutment stiffness on the response of Bridge \#l with flexible, instead of rigid, abutments were studied. The ratio of abutment stiffness to pier stiffness ranged from a value of 2 to infinity, all other parameters being held constant. A combined abutment and surrounding soil weight of $1500 \mathrm{kN}$ was assumed, this being about 1.5 times the pier weight. A second series of analyses was also carried out to determine the sensitivity of the bridge response to the value of the assumed contributory abutment and soil weights; a fixed value of abutment to pier stiffness ratio equal to 2 was assumed for this series of studies.

Figure 2 shows the effect of varying the stiffness ratio on bridge response. The natural period of the bridge changed from 0.81 seconds for the ratio equal to infinity i.e. rigid abutments, to 1.26 seconds for the ratio equal to 2 . The El Centro $1940 \mathrm{~N}-\mathrm{S}$ spectral acceleration
(Figure 4) reduces considerably over this period range, and this is clearly indicated by the reduction in the total abutment and pier shear force, although the reduction is almost entirely at the abutments.

It can be seen from Figure 2 that when the ratio of abutment stiffness to pier stiffness is 10 , the response is similar to the case of rigid abutments. The displacement responses generally all decrease with increasing abutment stiffness resulting from the increased lateral load resistance provided by the abutment. The pier shear force is not greatly affected by variations in the ratio of abutment to pier stiffness, but abutment shear forces increase rapidly as the stiffness ratio increases from 2 to 5 , but then only increases marginally as the stiffness ratio is increased further.

Figure 3 shows the effect of increasing the abutment and soil weight. for an abutment to pier stiffness ratio equal to 2. The displacements and forces increase as the abutment weight is increased. The abutment weight particularly affects the abutment substructure displacements and forces, but does not affect the abutment bearing displacements. Doubling the weight of the abutments from either 1000 to $2000 \mathrm{kN}$ or 1500 to $3000 \mathrm{kN}$, increases the deck displacement by approximately 13\%, has little effect on the abutment bearing displacements and increases the bearing displacements at the pier by $40 \%$. However, these bearing displacements correspond to maximum strains of only $28 \%$, less than the allowable maximum design value of $50 \%$.

\section{DIFFERENT EARTHQUAKE RECORDS.}

Some of the analyses using $E l$ Centro $1940 \mathrm{~N}-\mathrm{S}$ earthquake record and reported in [1], were re-run using three other earthquake records, namely El Centro 1979, Parkfield and the Artificial Bl. Each has a different intensity and the results are compared to determine whether similar trends hold for different earthquakes.

Table 2 shows that for all the four earthquake records the displacements are reduced when lead-rubber bearings are used instead of elastomeric bearings. The amount of reduction is approximately the same for all four records indicating that the lead-rubber bearings probably change response largely by increasing the viscous damping. Deck displacements are reduced to between 50-63\%, bearing displacements at the pier to between $30-45 \%$, and pier shear forces to between $65-75 \%$ of the responses for the bridge deck supported on elastomeric bearings, Bridge \#10.

It is clear from Table 2 that the magnitude of the response of the structure depends on the particular earthquake record used. The strongest structural response is caused by the Parkfield earthquake, El Centro 1979 and Artificial B1 induce smaller responses and El-Centro $1940 \mathrm{~N}-\mathrm{S}$ induces the smallest response. This 

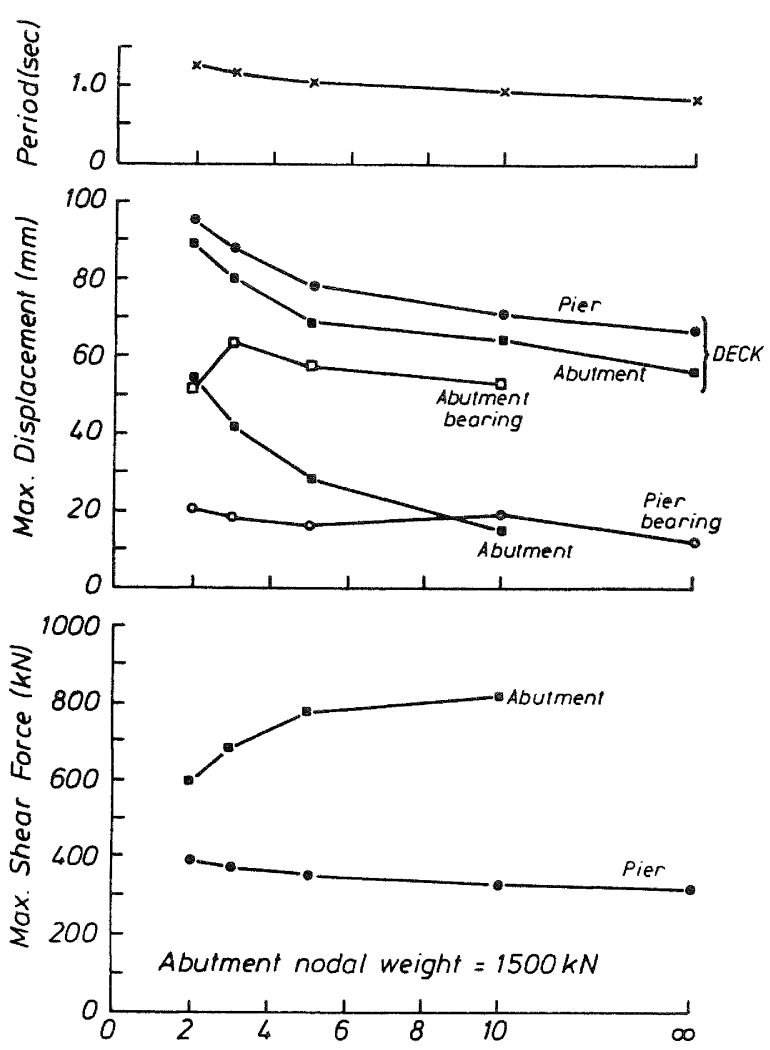

Ratio of Abutment to Pier Stiffnesses $\left(k_{a b} / k_{p}\right)$

Figure 2. Bridge response to changes in ratio of abutment to pier stiffness -- with lead-rubber; El Centro $1940 \mathrm{~N}-\mathrm{S}$.

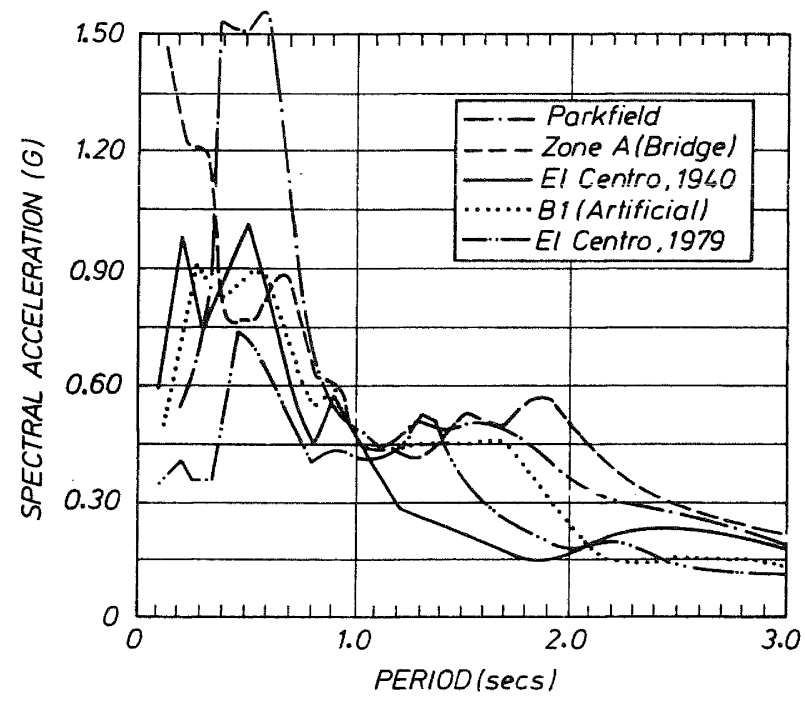

Figure 4. Spectral accelerations.
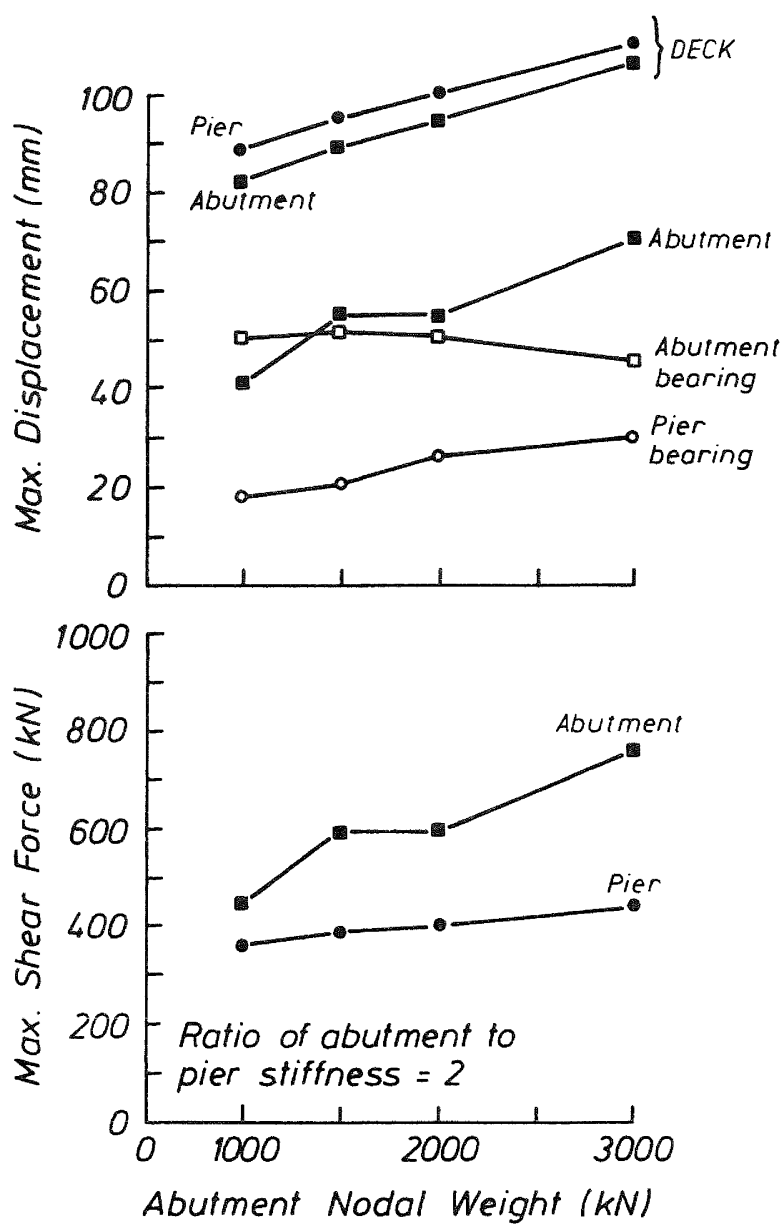

Eigure 3. Bridge response to changes in abutment and soil weights -- with leadrubber; El Centro $1940 \mathrm{~N}-\mathrm{S}$.

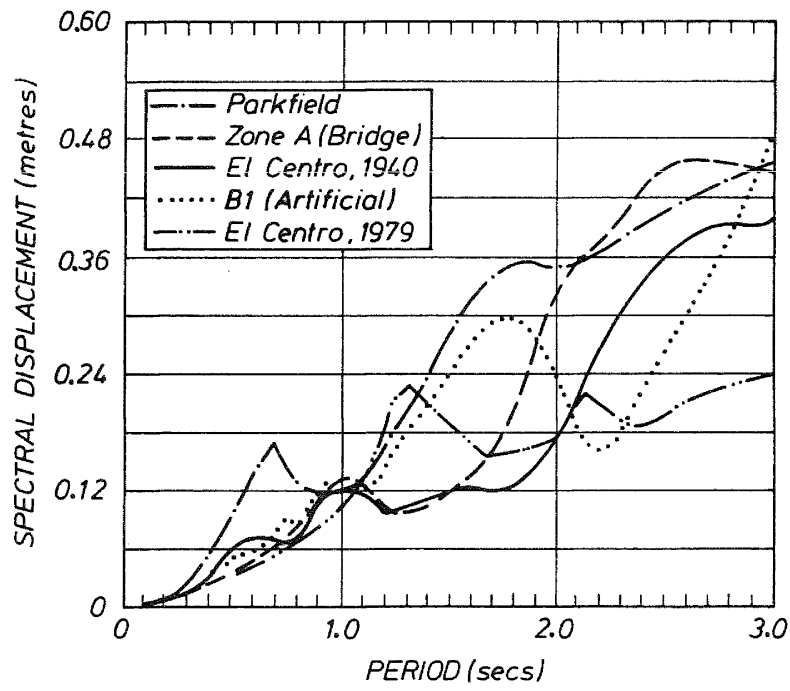

Figure 5. Spectral displacements. 


\begin{tabular}{|c|c|c|c|c|c|c|c|c|c|}
\hline & \multicolumn{4}{|c|}{ 4-Span Bridge with Elastomeric Bearings } & \multicolumn{4}{|c|}{ 4-Span Bridge with Leud-Rubber lxirings } \\
\hline \multicolumn{2}{|c|}{ Earthquake Reconds } & El Centro 40 & El Centro 79 & Parkfield & $\mathrm{B} 1$ & El Centro 40 & El Centro 79 & Parkfield & Bl \\
\hline \multicolumn{2}{|l|}{ Bridge Number } & 10 & 10 & 10 & 10 & 1 & 1 & 1 & 1 \\
\hline \multicolumn{2}{|c|}{ Natural Period (Sec) } & \multicolumn{4}{|c|}{1.49} & \multicolumn{4}{|c|}{0.81} \\
\hline \multirow{2}{*}{$\begin{array}{l}\text { Maximum } \\
\text { Deck } \\
\text { Displacement } \\
\text { (mi) }\end{array}$} & Abutment & 116.5 & 182.0 & 290.5 & 159.9 & 56.5 & 92.5 & 160.6 & 94.4 \\
\hline & Pier & 122.7 & 190.1 & 304.3 & 168.6 & 66.7 & 100.8 & 174.5 & 106.0 \\
\hline $\begin{array}{l}\text { Maximum } \\
\text { Bearing } \\
\text { Displacement } \\
(\mathrm{mm})\end{array}$ & Pier & 40.3 & 74.7 & 114.9 & 56.6 & 12.2 & 19.9 & 48.2 & 25.4 \\
\hline \multicolumn{2}{|l|}{$\begin{array}{l}\text { Maximum } \\
\text { Pier } \\
\text { Displacenent } \\
\text { (mm) }\end{array}$} & 82.9 & 117.0 & 193.7 & 114.0 & 58.0 & 82.7 & 128.3 & 79.4 \\
\hline $\begin{array}{l}\text { Maximum } \\
\text { Shear } \\
\text { Forøe (kN) }\end{array}$ & $\begin{array}{l}\text { Abutment } \\
\text { Pier }\end{array}$ & $\begin{array}{l}428.8 \\
448.6\end{array}$ & 669.6 & $\begin{array}{l}1069.0 \\
1029.5\end{array}$ & $\begin{array}{l}588.3 \\
617.1\end{array}$ & 440.0 & 634.3 & 1002.2 & $\begin{array}{l}644.9 \\
451.1\end{array}$ \\
\hline
\end{tabular}

TABLE 2 Analysis of bridges with isolating bearings for four earthquakes

statement holds irrespective of whether the deck is supported on elastomeric or leadrubber bearings. It is also clear from the elastic acceleration and displacement response spectra in Figures 4 and 5 , that at periods of 0.8 and 1.5 seconds, the Parkfield earthquake always induces the greatest response. These figures are drawn for 5\% critical damping and relate more closely to decks on elastomeric bearings. Those supported on lead-rubber bearings have a larger equivalent viscous damping ratio and the spectral displacements and accelerations will be smaller than shown in the Figures. The smallest response at 1.5 seconds is always for the El-Centro $1940 \mathrm{~N}-\mathrm{S}$ earthquake on which most bridge designs have been based. Acceleration and displacement response spectra have been derived from the New Zealand Bridge design Zone $A$ spectrum and are shown in Figures 4 and 5. El Centro $1940 \mathrm{~N}-\mathrm{S}$ and Zone $A$ spectral displacements coincide for periods between 1.0 and 1.6 seconds, but Zone $A$ coincides with Parkfield for these periods in the spectral acceleration plot.

The time-history plots of deck displacement in Figure 6 exhibit different characteristics for the four different earthquake records. The El Centro 1940 N-S earthquake gives intense shaking between 2 and 6 seconds and then peaks again at about 12 seconds. For the El Centro 1979 earthquake, the response only becomes significant after 5 seconds and has approximately the same length of period of strong shaking as the El Centro $1940 \mathrm{~N}-\mathrm{S}$ earthquake. The impulsive nature of the parkfield earthquake is shown by the short duration of strong shaking of about 2 seconds. The Artificial Bl earthquake is also impulsive in nature, lasting about 2 seconds, but preceded by 8 seconds of low level shaking.

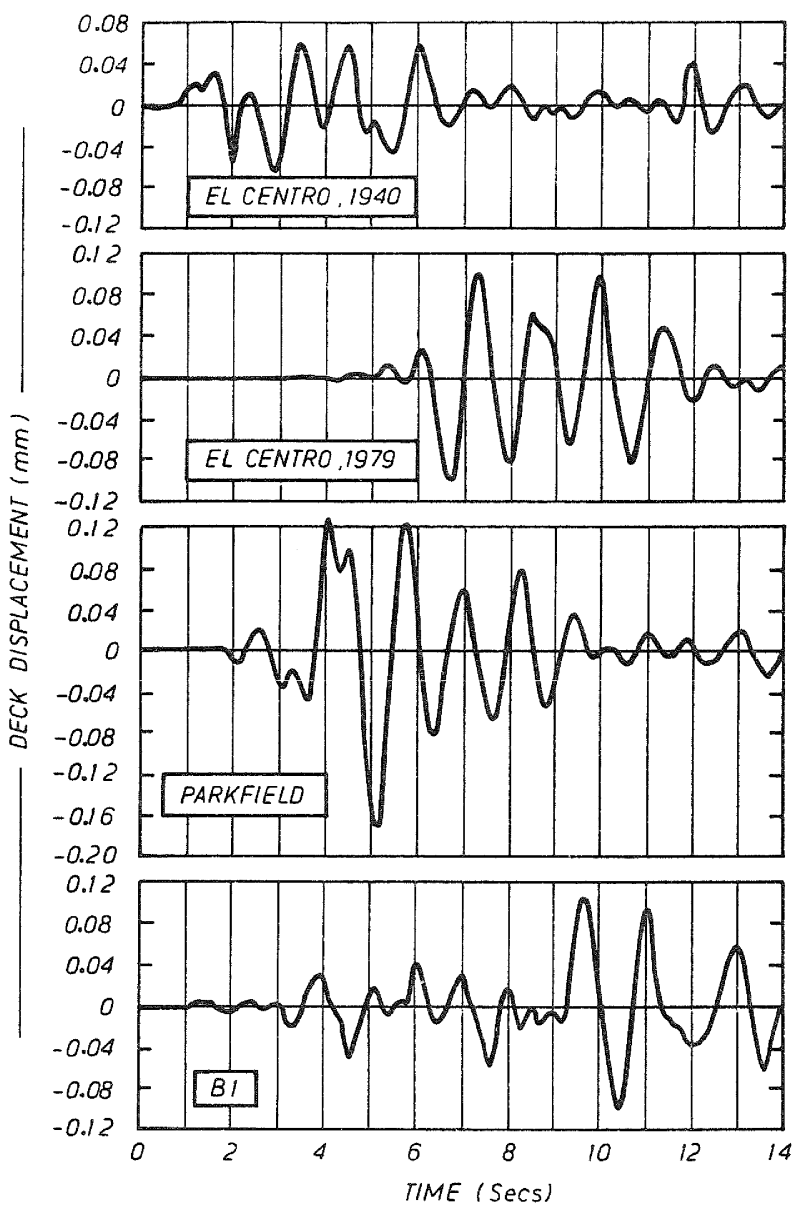

Figure 6. Time history of deck displacements at central pier for various earthquakes. 
The combined effect of variations in pier height and earthquake excitation on the maximum deck and bearing displacements at pier 2, is shown in Figure 7. The trends are the same for all earthquakes. The sum of deck and bearing displacement increases with longer piers and therefore with longer periods (from 0.63 to 0.88 seconds) in the same way that the spectral displacements increase. The greatest response is again for the parkfield earthquake and the smallest for $E 1$ centro $1940 \mathrm{~N}-\mathrm{S}$. The pier shear force decreases as the pier height increases and therefore for longer periods, in the same way that the spectral accelerations decrease. Again, responses are greatest for Parkfield and smallest for El Centro $1940 \mathrm{~N}-\mathrm{S}$. The substantial reduction in bearing displacment for the four earthquake records when the pier heights are $20 \mathrm{~m}$ again indicates that lead-rubber bearings are less effective in protecting flexible piers. This is because the more flexible piers are already being protected in that the deck forces are transmitted by the stiff superstructure to the abutment.
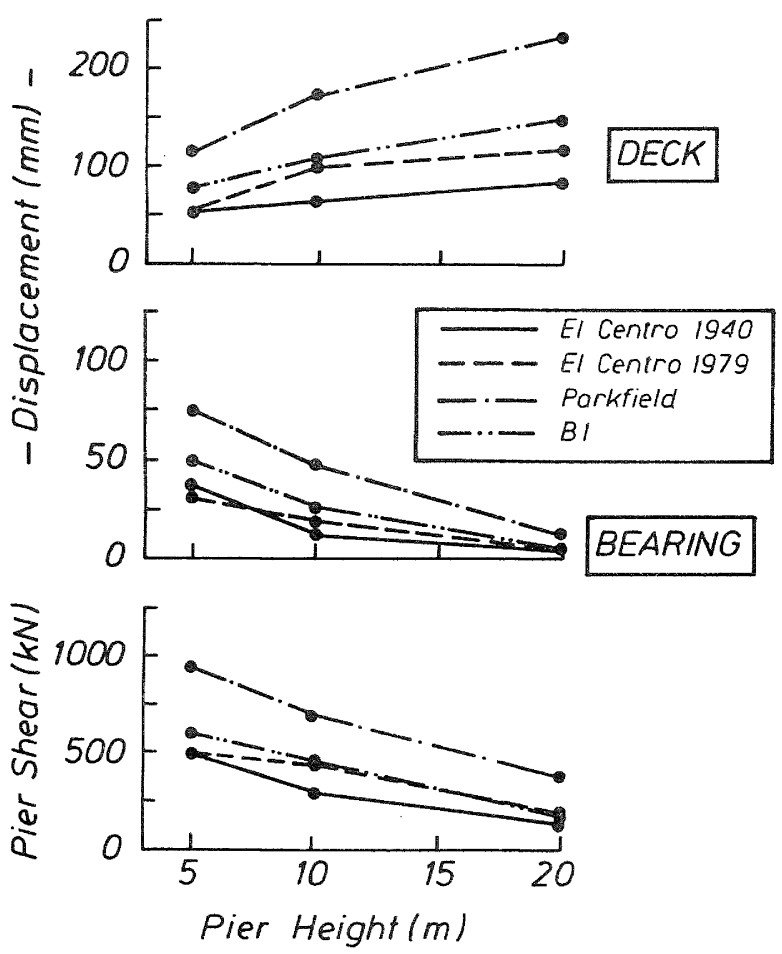

Figure 7. Bridge response at central pier to variations in pier height for various earthquakes.
Figure 8 shows the effect of span number and different earthquakes on bridge response. The El Centro 1979 and Parkfield earthquakes show decreasing deck displacement at the abutment instead of increasing, as the number of spans increases from 6 to 8 . Other than this variation, the graphs display similar increasing trends in all responses for the four earthquake spectra. The natural periods of the 4-, 6- and 8- span bridges are $0.8,1.1$ and 1.3 seconds respectively. The responses generally follow the earthquake spectra over this period range.

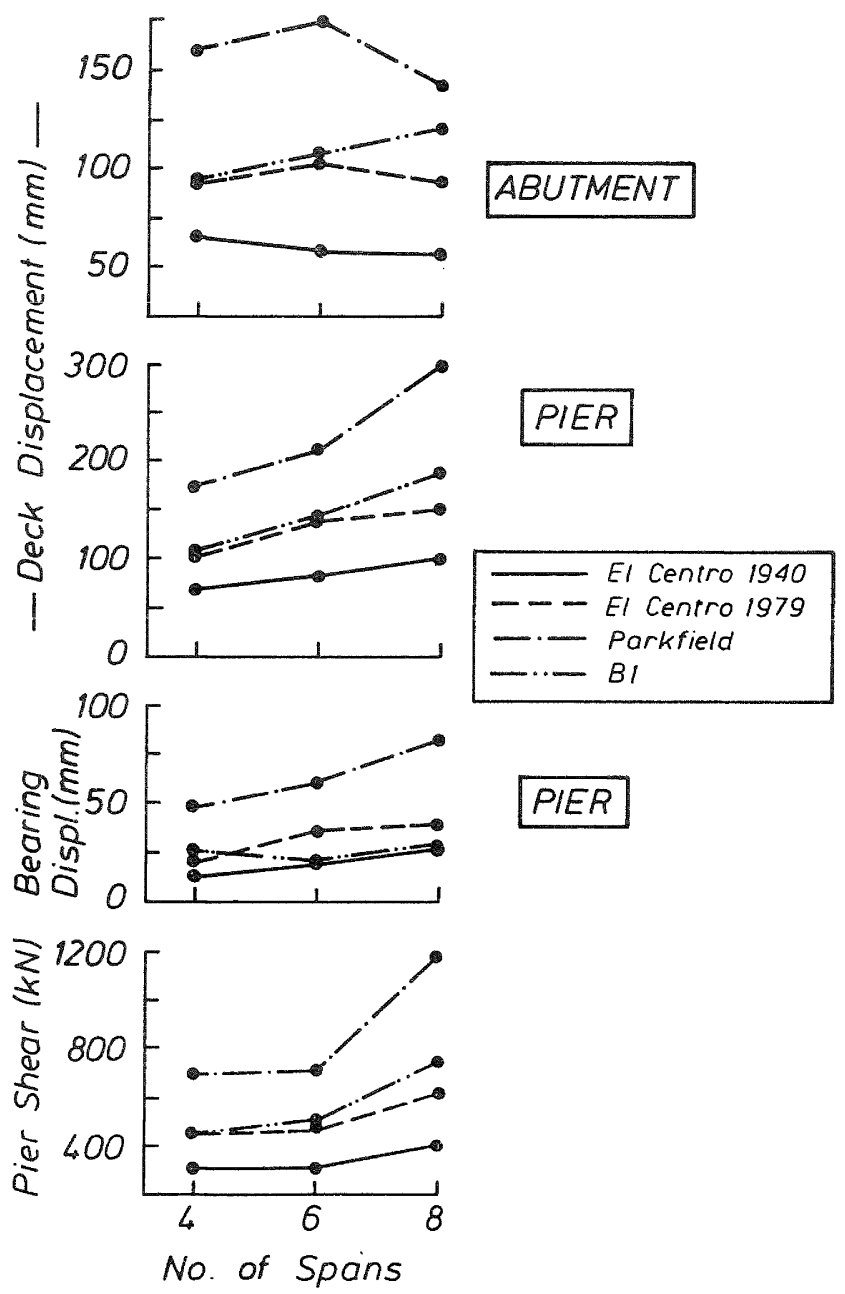

Figure 8. Bridge response for 4-, 6- and 8span continuous decks to various earthquakes. 


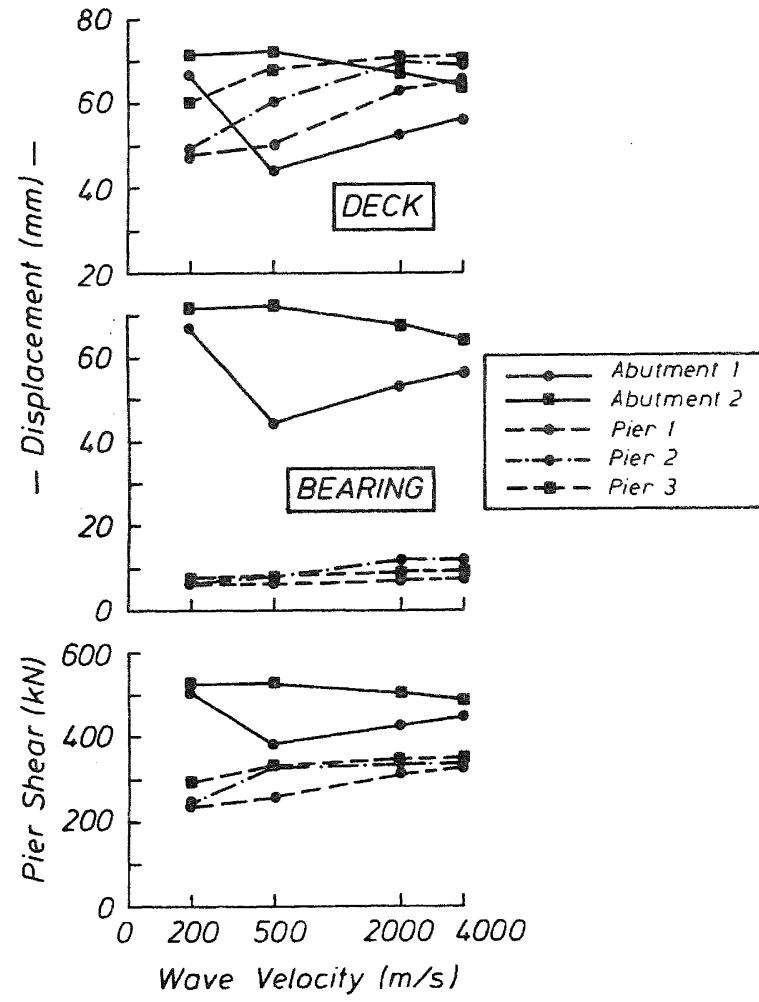

Figure 9. Effect of changes in velocity of longitudinally propagating transverse waves on the response of an 8-span bridge; El centro $1940 \mathrm{~N}-\mathrm{S}$.
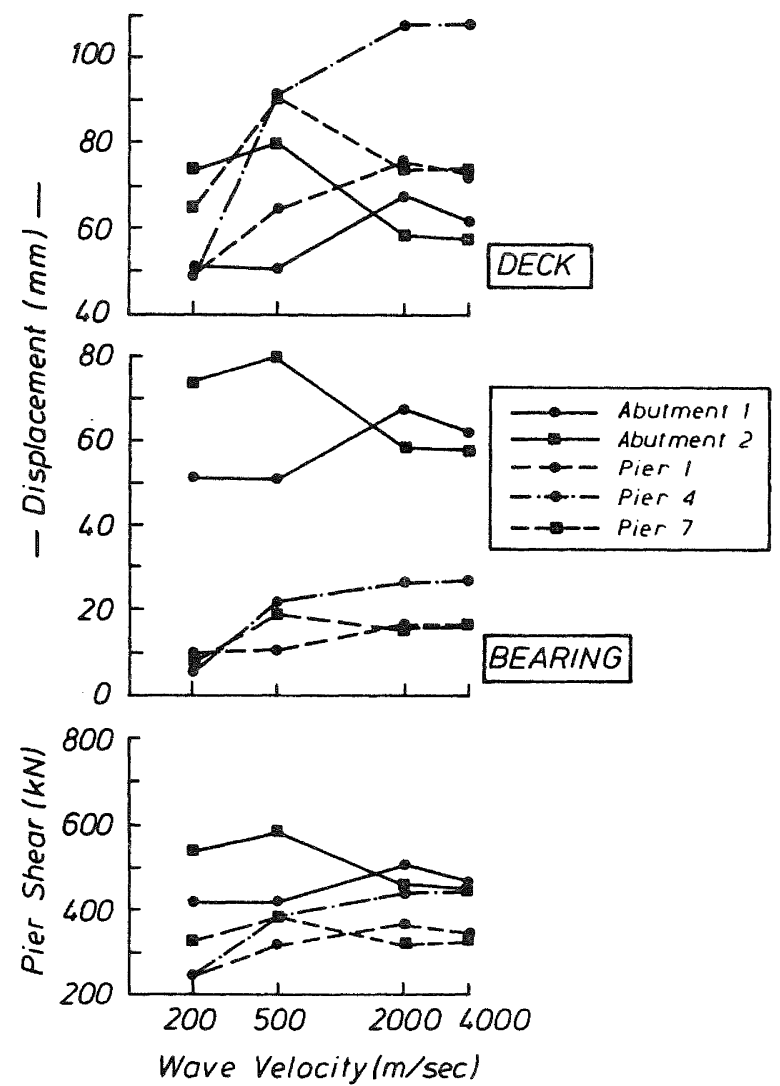

Figure 10. Effect of changes in velocity of longitudinally propagating transverse waves on the response of a 4-span bridge; El centro $1940 \mathrm{~N}-\mathrm{S}$.
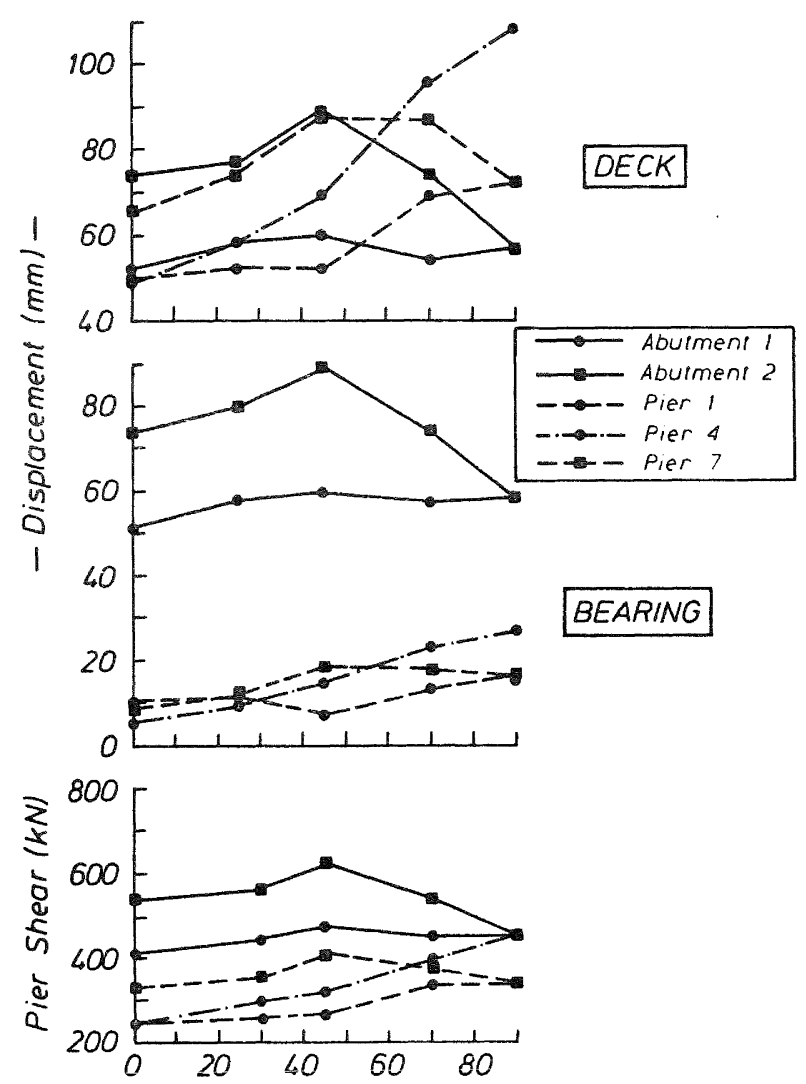

Angle of Wave Attack (degrees)

Figure 11. Effect of angle of wave attack on the response of an 8-span bridge; E1 Centro $1940 \mathrm{~N}-\mathrm{S}$.

(zero degrees--longitudinal propagation)

( 90 \& --transverse , )

PROPAGATING TRANSVERSE SEISMIC WAVES--EFFECT OF VARIATIONS IN VELOCITY AND ANGLE OF ATTACK.

Horizontal transverse shear waves were propagated at various velocities along a 4 span (Bridge \#1) and an 8-span bridge. The shear wave velocities used were $200 \mathrm{~m} / \mathrm{s}$ and $500 \mathrm{~m} / \mathrm{s}$ for soft materials and $2000 \mathrm{~m} / \mathrm{s}$ and $4000 \mathrm{~m} / \mathrm{s}$ for rock [2]. In a study of the 8-span bridge different angles of wave attack by a horizontally propagating transverse shear wave with a velocity of $200 \mathrm{~m} / \mathrm{s}$ were also considered. Results of the analyses are summarised in Figures 911 .

The effects of propagating seismic waves on a bridge will be important if the velocity of the wave is slow or if the bridge is long. The deformation of the deck of the 8-span bridge (Figure 9) is characterized by prominent flexural and torsional deformations when the shear wave velocity is $200 \mathrm{~m} / \mathrm{sec}$. The maximum deck displacements at the abutments are very different in this case. The torsional deformation is caused by a phase difference between the excitations applied to each foundation. Torsional deformation becomes 
less prominent as the wave velocity increases, and the behaviour of the deck changes to a largely flexural mode. At the greatest velocity, the maximum displacements at each abutment and at each outer.pier are approximately equal and the deck displacement at the central pier is approximately twice the displacement at the abutment. The effect of horizontally propagating waves at different velocities is less pronounced on the shorter bridge (see Eigure 10). The response of the bearings and dissipators to the travelling wave velocity is similar for both bridges and at the piers do not exceed the 50\% strain limit. However, the bearing strains at the abutment are subjected to approximately $70 \%$ strain. Pier shear forces are almost independent of bridge length, and the greatest spread occurs with low velocities.

The results of the analyses using different angles of wave attack are summarized in Figure 11: note that the angle of attack is measured from the longitudinal centreline of the bridge. The torsional and flexural deformations of the deck increase from zero to 45 degrees, after which the torsional effect decreases to zero at 90 degrees (i.e. the transverse shear wave reaches all the piers and abutments simultaneously) whilst the flexural effect continues to increase. When the angle of wave attack is 90 degrees, the deformation in the deck is symmetrical about the middle of the bridge, and the deck deformation is entirely due to flexure. Generally, Figures 9-1l show similar trends for deck displacement, bearing displacement and substructure forces. Deck and bearing displacements at the abutment are largest at an angle of attack of 45 degrees and smaller for angles both greater than and less than 45 degrees. At the central pier the deck displacement increases rapidly with increasing angle of attack and the bearing displacement also increases, but the strain never exceeds the $50 \%$ limit. The maximum pier shear force occurs at the central pier, at an angle of wave attack of 90 degrees, but the next smallest pier shear force occurs at an outer pier when the angle of wave attack is 45 degrees, produced by a combination of flexure and torsion.

\section{CONCLUSIONS.}

1. BEARING STIEENESS VARIATIONS.

The studies on the $+/-20 \%$ variations in bearing stiffnesses which allow for manufacturing tolerances and differences in material properties show that the effect on the structural response can be significant. It is however difficult to state any general conclusions because of the random nature of the variation in real bearing properties. The percentage variation in bearing stiffnesses, strength and post-yield stiffness of the dissipators have all been taken as equal whereas in reality, the variation in these three properties may be different. The abutments were assumed to be rigid, and so the response is most sensitive to variations in the properties of the abutment bearings, and much less sensitive to variations in the properties of the bearings on top of the $10 \mathrm{~m}$ piers.

2. ABUTMENTT STIEFNESS AND WEIGHT VARIATIONS.

The effects of variations in the abutment stiffness on the response of the structure considered in this study is significant for abutment to pier ratios less than 5 . When the ratio of the stiffness of the abutment to the pier exceeds a value of 10, the response of the structure is very similar to the case of rigid abutments. pier bearing displacement and pier shear forces are approximately constant and independent of abutment to pier stiffness ratio. It is probable that this ratio would have a more pronounced effect on the shear force if the pier heights had been $5 \mathrm{~m}$, thereby reducing the natural period of the structure. The trends follow the earthquake spectra, i.e. the deck displacements increase and shear forces decrease as the natural period of the structure increases. The response of the bridge to changes in abutment and contributing soil weights shows that as the weight is increased, the shear forces and deck displacements increase, as would be expected.

3. DIFFERENT EARTHQUAKES.

The deck displacement, bearing shear strain and displacements and the substructure forces are very sensitive to the characteristics of the earthquake records. Consistently throughout all responses, the parkfield earthquake produced the greatest response, approximately between 2 and 3 times the smallest response caysed by the El Centro $1940 \mathrm{~N}-\mathrm{S}$ earthquake. The effect of pier stiffness on response was studied by varying the pier height and the effect of deck stiffness by varying the number of spans. The effect of pier and deck stiffnesses on the bridge response show similar trends for the four earthquake records considered in this study. Generally, response increases with decreasing pier height and number of spans, the exceptions being the deck displacements at the central pier which increase with increasing pier height whilst those at the abutment are approximately constant with increasing number of spans. 
4. PROPAGATING SEISMIC WAVES-- VARIATIONS IN VELOCITIES AND ANGLES OF ATTACK.

The effects of horizontally propagating seismic waves on the bridge response will be pronounced if the bridge is long or is supported on soft foundation material associated with small wave velocities. Bridge design is carried out on the assumption that the bridge will be subjected to seismic waves which reach the piers and abutments simultaneously. The results of this study closest to that assumption are wave velocities through rock, travelling at $4000 \mathrm{~m} / \mathrm{s}$. A comparison of these results with the response for smaller velocities indicates that the design approach is reasonable for the 4-span bridge, but that for an 8-span bridge the deck and bearing displacements and the shear force at the abutments would be under-estimated and the pier responses would be overestimated. Bearing strains at the abutments generally exceed the $50 \%$ limit by as much as $20 \%$ Maximum responses at the abutments occur at a 45 degree angle of attack, being about $55 \%$ greater than the responses from the standard transverse attack. Pier displacements and shear forces generally increase with angle of attack and are maximum for the central pier with the wave propagating transversely. Responses change with angle of attack and it would be prudent to take this into account in design when further information becomes available.

\section{ACKNOWLEDGERENTS .}

This work was carried out as a Master of Engineering research project by Tan Fun Kwai supervised by the other co-authors. The authors gratefully acknowledge the financial support made by the Road Research Unit of the National Roads Board of New zealand.

\section{REFERENCES .}

1. Moss, P.J., Carr, A.J., Cooke, N. and Tan Fun Kwai, "The Influence of Bridge Geometry on the Seismic Behaviour of Bridges on Isolating Bearings", Bulletin of the New Zealand Society for Earthquake Engineering, Vol. 19, No. 4, pp. 255-262, Dec. 1986 .

2. Wolf, J.P., 'Dynamic Soil-Structure Interaction", Prentice-Hall. Englewood, California, New Jersey, 1985.

\section{NOTATION.}

$\mathrm{K}_{\mathrm{ab}} \begin{aligned} & \text { Combined stiffness of abutment plus } \\ & \text { elastomeric bearing, }\end{aligned}$
$\mathrm{K}_{\mathrm{b}} \begin{aligned} & \text { Shear stiffness of elastomeric } \\ & \text { bearing, }\end{aligned}$
$\mathrm{K}_{\mathrm{db}} \begin{aligned} & \text { Combined stiffness of lead-rubber } \\ & \text { bearings after } \\ & \text { elastomeric bearings, yielding plus }\end{aligned}$
$\mathrm{K}_{\mathrm{p}}$ Lateral stiffness of pier,
$\mathrm{G}$ Gravitational acceleration.

